\title{
Influence of Obstetric Practice on Workload and Practice Patterns of Family Physicians and Obstetrician-Gynecologists
}

\author{
Grabam M. Dresden, $M D^{1}$ \\ Laura-Mae Baldwin, MD, MPH \\ C. Holly A. Andrilla, MS ${ }^{2}$ \\ Susan M. Skillman, $M S^{2}$ \\ Thomas J. Benedetti, MD, MHA \\ 'Department of Family Medicine, Kaiser \\ Permanente Northwest, Portland, Oregon \\ ${ }^{2}$ Center for Health Workforce Studies, \\ Department of Family Medicine, University \\ of Washington, Seattle, Washington \\ ${ }^{3}$ Department of Obstetrics and Gynecol- \\ ogy, University of Washington, Seattle, \\ Washington
}

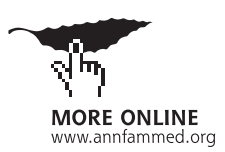

\begin{abstract}
PURPOSE Obstetric practice among family physicians has declined in recent years. This study compared the practice patterns of family physicians and obstetrician-gynecologists with and without obstetric practices to provide objective information on one potential reason for this decline-the impact of obstetrics on physician lifestyle.
\end{abstract}

METHODS In 2004, we surveyed all obstetrician-gynecologists, all rural family physicians, and a random sample of urban family physicians identified from professional association lists $(\mathrm{N}=2,564)$ about demographics, practice characteristics, and obstetric practices.

RESULTS A total of 1,197 physicians (46.7\%) overall responded to the survey (41.5\% of urban family physicians, $54.7 \%$ of rural family physicians, and $55.0 \%$ of obstetrician-gynecologists). After exclusions, 991 were included in the final data set. Twenty-seven percent of urban family physicians, $46 \%$ of rural family physicians, and $79 \%$ of obstetrician-gynecologists practiced obstetrics. The mean number of total professional hours worked per week was greater with obstetric practice than without for rural family physicians (55.4 vs 50.2, $P=.005$ ) and for obstetrician-gynecologists (58.3 vs 43.5, $P=.000$ ), but not for urban family physicians (47.8 vs $49.5, P=.27$ ). For all 3 groups, physicians practicing obstetrics were more likely to provide inpatient care and take call than physicians not practicing obstetrics. Large proportions of family physicians, but not obstetriciangynecologists, took their own call for obstetrics. Concerns about the litigation environment and personal issues were the most frequent reasons for stopping obstetric practice.

CONCLUSIONS Practicing obstetrics is associated with an increased workload for family physicians. Organizing practices to decrease the impact on lifestyle may support family physicians in practicing obstetrics.

Ann Fam Med 2008:6(suppl 1):s5-s11. DOI: 10.1370/afm.737.

\section{INTRODUCTION}

T 2006 , only $20 \%$ of family physicians reported practicing obstetrics. ${ }^{1}$ The percentage may continue to drop $; 2$ recent surveys of fam-

ily medicine residency graduates have shown a steady decline in the percentage practicing obstetrics over the past decade. ${ }^{2,3}$ The liability environment, insurance premium costs, and associated changes (eg, the decrease in consultant availability, the rise in cesarean delivery rate) have received the most attention as factors contributing to this decline. ${ }^{4-8}$ Another important factor that may contribute to the decline in obstetric practice among family physicians, however, is its perceived or real impact on lifestyle. A growing literature has documented that physicians increasingly are taking into account lifestyle issues such as weekly practice work hours and on-call responsibilities when making career decisions. ${ }^{9-11}$ Few 
studies have actually documented the relationship between obstetric practice and physician workload and lifestyle, however. ${ }^{12}$

This survey helps fill this information gap by examining the current practice patterns of both family physicians and obstetrician-gynecologists in Washington State, as well as the influence of practicing obstetrics on family physicians' and obstetrician-gynecologists' work patterns. It also describes the most common reasons for family physicians' and obstetrician-gynecologists' decisions to discontinue obstetrics. The results of this study can help facilitate the career decisions of medical students as well as residents in both family medicine and obstetrics and gynecology. The findings may also help practices understand organizational strategies that might facilitate recruitment and retention of obstetrically active physicians.

\section{METHODS}

We identified Washington State obstetrician-gynecologists and family physicians in early 2004 from membership lists of Washington State professional associations. Rural and urban family physicians were distinguished using the ZIP code version of the RuralUrban Commuting Areas (RUCA) classification, which combines census tract information and the standard Bureau of Census urban area and place definitions with commuting information to characterize all of the nation's census tracts and ZIP codes as to their rural and urban status and functional relationships. ${ }^{13,14}$

We mailed a 4-page questionnaire (shown in the Supplemental Appendix, available online-only at

\section{http://www.annfammed.org/cgi/content/full/6/}

im suppl_1/s5/DC1) to all obstetrician-gynecologists

and rural family physicians, and to a simple random sample of urban family physicians. The questionnaire asked about demographic and practice characteristics, liability insurance characteristics, practice changes and limitations due to liability insurance issues, current obstetric practice, obstetric practice history, and changes in the obstetric practice environment. The full questionnaire was mailed to nonresponders 2 additional times after the initial mailing. An abbreviated, 10 -item questionnaire was mailed to nonrespondent obstetrician-gynecologists and rural family physicians after the first 3 mailings. The University of Washington Institutional Review Board approved this research, and participants gave informed consent through their response to the questionnaire. Survey findings related to liability insurance issues and their relationship to practice patterns have been published previously. ${ }^{7}$

Data were analyzed using version 14.0 of SPSS for Microsoft Windows (SPSS Inc, Chicago, Illinois).
We first compared the demographic and practice characteristics, obstetric practices, and reasons for stopping obstetrics between the 3 physician groups using standard unpaired $t$ tests for continuous variables and $\chi^{2}$ tests for categorical variables. We then compared the workload as well as inpatient and on-call practices between physicians who did and did not practice obstetrics within each physician group using the same statistical methods.

\section{RESULTS}

We sent 2,564 questionnaires to 1,157 urban family physicians, 579 rural family physicians, and 828 obstetrician-gynecologists. We had initial response rates of $41.5 \%, 54.7 \%$, and $55.0 \%$, respectively. After excluding physicians who were not currently practicing, were out of state, or were in training programs, the final data set included 382 urban family physicians, 272 rural family physicians, and 337 obstetrician-gynecologists. Only 30 obstetrician-gynecologists $(8.9 \%)$ were practicing in rural areas, so we combined the rural and urban obstetrician-gynecologists in our analysis.

Physicians were asked to estimate the number of births they attended in 2003, and more than $90 \%$ responded to this question. Weighting these responses to the total obstetric practitioner population resulted in a statewide estimate of births that was very close to the actual number of live births in Washington in $2003,{ }^{15}$ suggesting that our respondents were quite representative of the state's physicians in their obstetric practices.

The 3 physician groups were similar in several demographic characteristics (age, race) and practice type (Table 1). Obstetrician-gynecologists were the most likely to be female, whereas rural family physicians were the least likely. Obstetrician-gynecologists and rural family physicians were most likely to be selfemployed, whereas urban family physicians were most likely to work in health maintenance organizations and other nonprofit clinics.

Most obstetrician-gynecologists practiced obstetrics, whereas less than one-half of rural family physicians and slightly more than one-quarter of urban family physicians did so (Table 2). Virtually all obstetrician-gynecologists performed instrumented deliveries and cesarean deliveries. The majority of urban and rural family physicians performed instrumented deliveries, whereas essentially no urban family physicians and about one-third of rural family physicians performed cesarean deliveries. On average, both urban and rural family physicians attended about 2 deliveries monthly, whereas obstetrician-gynecologists attended about 10 monthly. The majority of 


\begin{tabular}{|c|c|c|c|}
\hline Measure & $\begin{array}{l}\text { Urban Family } \\
\text { Physicians } \\
\text { (n= 265) }\end{array}$ & $\begin{array}{c}\text { Rural Family } \\
\text { Physicians } \\
(n=140)\end{array}$ & $\begin{array}{l}\text { Obstetrician- } \\
\text { Gynecologists } \\
\text { (n=69) }\end{array}$ \\
\hline $\begin{array}{l}\text { Previously practiced obstet- } \\
\text { rics, n (\% yes)* }\end{array}$ & $257(71.1)$ & $139(79.1)$ & $69(82.6)$ \\
\hline $\begin{array}{l}\text { Would consider restarting } \\
\text { obstetrics, n (\% yes) }\end{array}$ & $181(23.2)$ & $99(23.2)$ & $46(19.6)$ \\
\hline $\begin{array}{l}\text { Reasons for stopping } \\
\text { obstetrics, } n\end{array}$ & 181 & 110 & 57 \\
\hline \multicolumn{4}{|l|}{ Litigation environment } \\
\hline First reason listed, \%* & 22.1 & 36.4 & 36.8 \\
\hline Listed at all, \% ${ }^{\dagger}$ & 55.2 & 72.7 & 68.4 \\
\hline \multicolumn{4}{|l|}{ Personal } \\
\hline First reason listed, \%* & 27.6 & 15.5 & 19.3 \\
\hline Listed at all, $\%^{\dagger}$ & 66.9 & 46.4 & 52.6 \\
\hline \multicolumn{4}{|l|}{ Practice environment } \\
\hline First reason listed, \%* & 7.7 & 10.9 & 0.0 \\
\hline Listed at all, \% ${ }^{\ddagger}$ & 39.2 & 54.5 & 8.8 \\
\hline \multicolumn{4}{|l|}{ Age related } \\
\hline First reason listed, \%キ & 0.0 & 1.8 & 8.8 \\
\hline Listed at al, $\%^{\dagger}$ & 8.8 & 6.4 & 22.8 \\
\hline \multicolumn{4}{|l|}{ Professional focus change } \\
\hline First reason listed, \% & 5.0 & 0.9 & 3.5 \\
\hline Listed at all, \%* & 22.1 & 10.9 & 28.1 \\
\hline $\begin{array}{l}\text { Note: The } \mathrm{n} \text { values indicate the } \mathrm{n} \\
\text { * } P \leq .05 \text {. } \\
\dagger P \leq .01 . \\
\neq P \leq .001 .\end{array}$ & ber of respondents fo & hat measure. & \\
\hline
\end{tabular}

Among those taking call, the mean number of monthly on-call hours was similar for both rural and urban family physicians, regardless of obstetric practice status. On the other hand, those obstetrician-gynecologists who did not practice obstetrics had a significantly higher mean number of monthly on-call hours, but a significantly lower mean number of monthly on-call patients than their counterparts who practiced obstetrics.

\section{DISCUSSION}

The decision of whether to practice obstetrics is a difficult one for many family physicians; it often involves financial, practical, legal, and lifestyle considerations. This study provides objective information about the impact of including obstetrics on family physicians' and obstetrician-gynecologists' practices that can guide physicians as they make their practice decisions. We found that rural family physicians and obstetriciangynecologists who practiced obstetrics had heavier workloads than their counterparts who did not. Their mean number of professional hours was greater, and they were more likely to provide inpatient care and take call than those not practicing obstetrics. Although obstetric practice was not associated with an increase in the mean weekly professional hours of urban family physicians, as for their rural counterparts, it was associated with a greater likelihood of providing inpatient care and on-call services. Comparison with results from a survey of licensed obstetrician-gynecologists in Washington State in 1998-1999 reveals that the obstetrician-gynecologists in our study were working more total professional hours, had more weekly outpatient visits, attended a greater number of deliveries per year, and spent a higher proportion of total hours in direct patient care. ${ }^{16}$ This pattern suggests that over the course of 5 years, the workload for physicians practicing obstetrics has increased. These findings, alongside reports that physicians increasingly seek careers with more controllable lifestyles, could help explain the increasing attrition from obstetrics. ${ }^{9-11}$

The reasons that physicians listed for discontinuing obstetrics in our study also support the importance of a controllable lifestyle to family physicians. There was a strong role for personal issues, such as wanting more personal time, especially for urban family physicians. At the same time, a large percentage of both urban and rural family physicians reported taking their own obstetric call, a practice that certainly decreases the availability of unrestricted personal time. These results suggest that making changes to practice organization, such as circumventing solo call or using obstetrically active hospitalists (so-called laborists), ${ }_{1}^{17}$ might make obstetric practice a more viable component of family physicians' practices.

The worsening medical liability milieu has been suggested as a substantial contributor to the increasing attrition from obstetrics in multiple studies, ${ }^{18-21}$ although some studies have disputed this association. ${ }^{22,23}$ Our study's findings support this concern, as between one-half and three-quarters of those physicians who had stopped practicing obstetrics listed some aspect of the litigation environment, including the affordability of malpractice insurance, as a contributor to their decision to quit. At the same time, prior research has demonstrated that changing the malpractice environment will not necessarily affect physicians' likelihood of practicing obstetrics. Nesbitt et $\mathrm{al}^{24}$ surveyed a group of family physicians and identified 


\begin{tabular}{|c|c|c|c|c|c|c|c|c|c|}
\hline \multirow[b]{2}{*}{ Measure } & \multicolumn{3}{|c|}{ Urban Family Physicians } & \multicolumn{3}{|c|}{ Rural Family Physicians } & \multicolumn{3}{|c|}{ Obstetrician-Gynecologists } \\
\hline & $\begin{array}{c}\text { Yes } \\
(n=100)\end{array}$ & $\begin{array}{c}\text { No } \\
(n=265)\end{array}$ & $\begin{array}{c}P \\
\text { Value }\end{array}$ & $\begin{array}{c}\text { Yes } \\
(n=120)\end{array}$ & $\begin{array}{c}\text { No } \\
(n=140)\end{array}$ & $\begin{array}{c}P \\
\text { Value }\end{array}$ & $\begin{array}{c}\text { Yes } \\
(n=242)\end{array}$ & $\begin{array}{c}\text { No } \\
(n=69)\end{array}$ & $\begin{array}{c}P \\
\text { Value }\end{array}$ \\
\hline \multicolumn{10}{|l|}{$\begin{array}{l}\text { Total professional hours } \\
\text { per week }\end{array}$} \\
\hline No. responding & 100 & 261 & & 104 & 126 & & 238 & 58 & \\
\hline Mean no. of hours & 47.8 & 49.5 & .27 & 55.4 & 50.2 & .005 & 58.3 & 43.5 & .000 \\
\hline \multicolumn{10}{|l|}{$\begin{array}{l}\text { Patient care hours spent } \\
\text { per week }\end{array}$} \\
\hline No. responding & 100 & 261 & & 104 & 126 & & 238 & 58 & \\
\hline $\begin{array}{l}\text { Direct patient care hours, } \\
\text { mean \% }\end{array}$ & 82.8 & 85.5 & .23 & 88.6 & 87.6 & .47 & 87.0 & 79.3 & .009 \\
\hline $\begin{array}{l}\text { Indirect patient care hours, } \\
\text { mean } \%\end{array}$ & 18.0 & 14.6 & .14 & 11.6 & 12.5 & .51 & 12.8 & 20.9 & .006 \\
\hline \multicolumn{10}{|l|}{$\begin{array}{l}\text { Direct patient care hours } \\
\text { spent per week }\end{array}$} \\
\hline No. responding & 99 & 258 & & 104 & 127 & & 231 & 56 & \\
\hline Ambulatory clinics, mean \% & 85.5 & 89.9 & .06 & 78.8 & 81.2 & .37 & 65.7 & 76.9 & .000 \\
\hline $\begin{array}{l}\text { Hospital inpatient settings, } \\
\text { mean } \%\end{array}$ & 9.3 & 4.1 & .000 & 13.1 & 7.4 & .000 & 21.9 & 11.2 & .000 \\
\hline Other settings, mean \% & 5.2 & 6.1 & .69 & 8.1 & 11.4 & .17 & 12.4 & 12.0 & .84 \\
\hline \multicolumn{10}{|l|}{ Weekly outpatient visits } \\
\hline No. responding & 100 & 259 & & 103 & 126 & & 233 & 57 & \\
\hline Mean no. & 77.7 & 84.2 & .11 & 83.6 & 81.9 & .66 & 74.9 & 47.6 & .000 \\
\hline \multicolumn{10}{|l|}{ Provide inpatient care } \\
\hline No. responding & 99 & 250 & & 101 & 122 & & 233 & 57 & \\
\hline Yes, \% & 84.8 & 45.2 & .000 & 96.0 & 70.5 & .000 & 100.0 & 70.2 & .000 \\
\hline \multicolumn{10}{|l|}{$\begin{array}{l}\text { Among those providing } \\
\text { inpatient care }\end{array}$} \\
\hline No. responding & 84 & 113 & & 97 & 86 & & 233 & 40 & \\
\hline $\begin{array}{l}\text { Mean no. of weekly inpa- } \\
\text { tient visits }\end{array}$ & 4.2 & 5.1 & .15 & 8.3 & 7.7 & .52 & 10.5 & 6.4 & .001 \\
\hline \multicolumn{10}{|l|}{ Take call } \\
\hline No. responding & 92 & 242 & & 96 & 120 & & 228 & 54 & \\
\hline Yes, \% & 97.8 & 79.8 & .000 & 97.9 & 84.2 & .000 & 99.6 & 68.5 & .000 \\
\hline \multicolumn{10}{|l|}{ Among those taking call } \\
\hline \multicolumn{10}{|l|}{ Monthly on-call hours } \\
\hline No. responding & 90 & 193 & & 94 & 101 & & 227 & 37 & \\
\hline Mean no. of hours & 96.8 & 109.2 & .39 & 122.2 & 141.3 & .36 & 119.5 & 201.6 & .03 \\
\hline \multicolumn{10}{|l|}{ Monthly on-call patients } \\
\hline No. responding & 84 & 148 & & 89 & 90 & & 221 & 36 & \\
\hline Mean no. of patients & 10.7 & 26.5 & .04 & 16.3 & 22.1 & .18 & 19.3 & 6.9 & .000 \\
\hline
\end{tabular}

those who had recently stopped practicing obstetrics and indicated that they would consider resuming obstetric practice if malpractice premium costs were lowered. One year later, they resurveyed the group after the major malpractice insurer lowered malpractice premiums by $25 \%$, but none of the respondents had restarted or were planning to resume obstetrics. This finding suggests that the impact of lifestyle factors on physicians' decisions to practice obstetrics is important.

Our study also documented that family physicians, especially those in rural areas, cared for a greater proportion of Medicaid obstetric patients than did obstetrician-gynecologists, although in absolute num- bers, obstetrician-gynecologists cared for the majority of such patients. Family physicians commonly provide obstetric care in rural areas; therefore, access of Medicaid patients depends heavily on family physicians continuing their obstetric practices. Because decreased access to obstetric care has been linked to worse birth outcomes, ${ }^{25-27}$ maintaining obstetrics as an integral part of rural family physicians' practices is very important to the rural population.

The extent to which the results of this study can be generalized to the entire population of family physicians and obstetrician-gynecologists may be limited. The roughly $50 \%$ response rate subjects the results 
to the possibility of nonresponse bias. It is encouraging that the weighted number of reported deliveries for 2003 is within 7\% of the number of live births reported by Washington's vital records system in 2003, suggesting that the survey respondents' obstetric volumes are representative of those of the state's physicians. Having the same obstetric volumes, however, does not ensure that the responding physicians necessarily had the same practice characteristics, history, or composition. This potential response bias, as well as a lack of information on nonrespondents so that we could evaluate the representativeness of our sample, is a limitation of this study.

Some inconsistencies in the physicians' responses to our questions about on-call hours suggest another study limitation. More obstetrically active family physicians than obstetrician-gynecologists took their own call for obstetric patients, yet they had fewer call hours than obstetrician-gynecologists and no more call hours than family physicians not practicing obstetrics. This finding suggests that family physicians may have recorded only the formal on-call hours for their practices when answering this question, thus underestimating the impact of taking their own call for obstetric patients in this survey.

This study helps elucidate the influence of obstetrics on the lifestyle of practicing physicians and suggests that obstetric practice does increase physicians' workload. This greater workload could influence not only family physicians' choices regarding obstetric practice, but also interest in family medicine as a specialty, which is declining. ${ }^{28}$ Medical students who are increasingly interested in specialties with controllable lifestyles may not choose family medicine with its continued training in obstetrics. To provide additional information to medical students and physicians to inform their career choices, future research might examine the practice patterns and satisfaction of physicians who have stopped practicing obstetrics to determine whether the expected gains truly bear out, and to identify the impact of terminating obstetrics on the financial viability of their practices. Additional research should explore whether alternative practice arrangements, such as more extensive shared call systems for family physicians practicing obstetrics, would help stem the tide of family physicians relinquishing this timehonored tradition that serves our practices' families.

To read or post commentaries in response to this article, see it online at http://www.annfammed.org/cgi/content/full/6/suppl_1/s5.

Submitted April 18, 2007; submitted, revised, July 27, 2007; accepted August 1, 2007.

Key words: Family medicine; obstetrics; practice patterns; workload; lifestyle; rural health care
Funding support: Provided by US Health Resources and Services Administration, Bureau of Health Professions, National Center for Health Workforce Analysis, grant 1 U79 HP 00007-0.

Acknowledgments: The authors would like to thank Elise Bowditch for her work in developing the database used in this research.

\section{References}

1. American Academy of Family Physicians. Performance of OB routine delivery in hospital practices of family physicians by census division, October 2006. http://www.aafp.org/online/en/home/ aboutus/specialty/facts/34.html. Accessed: July 26, 2007.

2. Ringdahl E, Delzell JE Jr, Kruse RL. Changing practice patterns of family medicine graduates: a comparison of alumni surveys from 1998 to 2004. J Am Board Fam Med. 2006;19(4):404-412.

3. Chen FM, Huntington J, Kim S, Phillips WR, Stevens NG. Prepared but not practicing: declining pregnancy care among recent family medicine residency graduates. Fam Med. 2006;38(6):423-426.

4. Ryan K, Schnatz P, Greene J, Curry S. Change in cesarean section rate as a reflection of the present malpractice crisis. Conn Med. 2005;69(3):139-141.

5. Hamilton BE, Martin JA, Ventura SJ. Births: preliminary data for 2005. Natl Vital Stat Rep. 2006;55(11):1-18.

6. Hale RW. Legal issues impacting women's access to care in the United States - the malpractice insurance crisis. Int J Gynaecol Obstet. 2006;94(3):382-385.

7. Benedetti TJ, Baldwin LM, Skillman SM, et al. Professional liability issues and practice patterns of obstetric providers in Washington State. Obstet Gynecol. 2006;107(6):1238-1246.

8. Studdert DM, Mello MM, Sage WM, et al. Defensive medicine among high-risk specialist physicians in a volatile malpractice environment. JAMA. 2005;293(21):2609-2617.

9. Dorsey ER, Jarjoura D, Rutecki GW. Influence of controllable lifestyle on recent trends in specialty choice by US medical students. JAMA. 2003;290(9):1173-1178.

10. Dorsey ER, Jarjoura D, Rutecki GW. The influence of controllable lifestyle and sex on the specialty choices of graduating U.S. medical students, 1996-2003. Acad Med. 2005;80(9):791-796.

11. Newton DA, Grayson MS, Thompson LF. The variable influence of lifestyle and income on medical students' career specialty choices: data from two U.S. medical schools, 1998-2004. Acad Med. 2005;80(9):809-814.

12. Rodney WM, Hardison D, Rodney-Arnold K, McKenzie L. Impact of deliveries on the office practice of family medicine. J Natl Med Assoc. 2006;98(10):1685-1690.

13. WWAMI Rural Health Research Center. Rural-Urban Commuting Area Codes (Version 2.0). http://depts.washington.edu/uwruca/. Accessed: February 1, 2007.

14. Morrill R, Cromartie J, Hart LG. Metropolitan, urban, and rural commuting areas: toward a better depiction of the US settlement system. Urban Geogr. 1999;20:727-748.

15. Centers for Disease Control and Prevention. National Center for Health Statistics. Birth data. February 1, 2007. http://www.cdc.gov/ nchs/births.htm. Accessed February 1, 2007.

16. Benedetti TJ, Baldwin LM, Andrilla CH, Hart LG. The productivity of Washington State's obstetrician-gynecologist workforce: does gender make a difference? Obstet Gynecol. 2004;103(3):499-505.

17. Weinstein $L$. The laborist: a new focus of practice for the obstetrician. Am J Obstet Gynecol. 2003;188(2):310-312.

18. Donlen J, Puro JS. The impact of the medical malpractice crisis on OB-GYNs and patients in southern New Jersey. $N \mathrm{~J}$ Med. 2003;100(9):12-19. 
19. Pathman D, Tropman S. Obstetrical practice among new rural family physicians. J Fam Pract. 1995;40(5):457-464.

20. Gordon RJ, McMullen G, Weiss BD, Nichols AW. The effect of malpractice liability on the delivery of rural obstetrical care. J Rural Health. 1987;3(1):7-13.

21. Hart-Hester S, Arthur CR, Olutade J, Beebe D, Replogle W. Factors that influence obstetrical care by Mississippi family physicians. J Miss State Med Assoc. 2002;43(6):173-179.

22. Grumbach K, Vranizan K, Rennie D, Luft HS. Charges for obstetric liability insurance and discontinuation of obstetric practice in New York. J Fam Pract. 1997;44(1):61-70.

23. Smits AK, Clark EC, Nichols M, Saultz JW. Factors influencing cessation of pregnancy care in Oregon. Fam Med. 2004;36(7):490-495.

24. Nesbitt TS, Arevalo JA, Tanji JL, Morgan WA, Aved B. Will family physicians really return to obstetrics if malpractice insurance premiums decline? J Am Board Fam Pract. 1992;5(4):413-418.
25. Allen DI, Kamradt JM. Relationship of infant mortality to the availability of obstetrical care in Indiana. J Fam Pract. 1991;33(6): 609-613.

26. Nesbitt TS, Connell FA, Hart LG, Rosenblatt RA. Access to obstetric care in rural areas: effect on birth outcomes. Am J Public Health. 1990;80(7):814-818.

27. Nesbitt TS, Larson EH, Rosenblatt RA, Hart LG. Access to maternity care in rural Washington: its effect on neonatal outcomes and resource use. Am J Public Health. 1997;87(1):85-90.

28. Pugno PA, McPherson DS, Schmittling GT, Kahn NB Jr. Results of the 2003 National Resident Matching Program: family practice. Fam Med. 2003;35(8):564-572. 